COPIM • Books Contain Multitudes: Exploring Experimental Publishing (2022 update)

\title{
Part 1: Mapping \& Situating Experimental Books
}

Janneke Adema ${ }^{1}$, Marcell Mars, Tobias Steiner ${ }^{1}$, Simon Bowie ${ }^{1}$

${ }^{1}$ Centre for Postdigital Cultures, Coventry University

Published on: Apr 26, 2022

DOI: 10.21428/785a6451.0ed93b68

License: Creative Commons Attribution 4.0 International License (CC-BY 4.0). 


\section{Mapping Experimental Books}

The first part of this report seeks to map some of the different kinds of experiments that are currently taking place within the realm of scholarly book publishing. This includes experiments with the form and format of the scholarly book; with the various (multi)media through which books can be performed; and with the ways in which scholarship can be produced, disseminated, and consumed, as well as reviewed, reused, and interacted with. But it also includes experiments that reimagine the relationalities that constitute academic writing, research, and publishing, that want to rethink what research, scholarly communication and publishing are or do, and how they are currently organised. As such this report includes various speculations on what the future of the book and the humanities could look like, which we hope will inspire both publishers and authors to explore publication options that move beyond the printed codex-format as the standard publication choice, and that challenge the dominance of print-based processes within academic publishing (as being natural and the most suitable for all forms of research). Based on desk research, this report provides a ty.pology of different types and forms of scholarly books, based on various experiments currently being conducted within academia, accompanied by a selection of examples to illustrate each of the different types identified.

Why map experimental publishing? Partly because there remains a gap between the professed need of publishers and academics to experiment more with (digital) media and the forms and formats the scholarly book can accommodate, and the expertise, skill sets, tools and technologies, and funding they have to actually do so (Adema \&

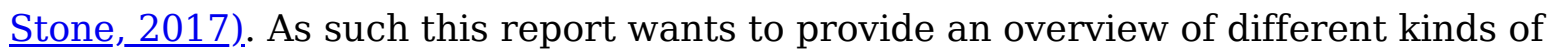
experiments to illustrate what is possible within this realm and what alternative forms and relationalities presses and authors are already experimenting with. This is to both promote and give visibility to the rich and diverse forms of digital scholarship, and multimodal and interactive research out there, and to help and inspire other presses and authors to conduct similar experiments themselves.

The focus in this report is on experimental books created with open source software, tools, or platforms (an overview of which will be provided in section three of this report), i.e., digital publishing tools that presses and authors can either freely use and/or further adapt themselves within their workflows. But beyond providing an overview of alternative publishing options, perhaps most importantly this report wants to map and build communities. Emphasising the political and socio-technical nature of 
our publishing tools and infrastructures (․kune et al.,2018), we hope this report will help establish relationships between software and tool providers, publishers, and authors, and create communities of expertise around experimental books. For technology providers this might lead to a further community uptake and adoption of the digital publishing tools they have created to support new forms of publishing. For presses and authors it provides them with examples to draw inspiration from, next to an overview of tools and technologies currently available to support these publishing experiments-as well as a way to potentially connect to the open source communities that maintain these tools and infrastructures, which might lead to further collaborations. But most importantly, we hope that establishing these kinds of relationships will further enable and bring about the more equitable and communityled not-for-profit ecosystem to support academic book publishing that COPIM wants to help strengthen and bring about.

Although we hope that the typology as outlined in the second part of this report (see the addendum) will be a useful resource to these communities, it is not intended to provide a fixed classification or a definite delineation of different types of experimental books. As such it doesn't provide any clear-cut definitions of the various experiments undertaken within scholarly book publishing -if only because many of the examples discussed in this report will not always fit easily or comfortably within the categories identified here; many will also use alternative terminology to define and classify themselves, which differs from the ones applied here in this report to gather and collect different experiments together; and some will cross or integrate several categories within one project. Hence this typology does not neatly mirror the current landscape, nor will it be exhaustive. New experiments are already being undertaken and will change the categories identified here (merging them, solidifying them etc.). As such this mapping only provides a snapshot, a temporary overview and analysis, one that will hopefully be updated, revised, and re-used in different contexts.

In this respect analysing experimental publishing-perhaps more than established forms of publishing-requires a continuous re-mapping due to the nature of its speculative and emergent form, where any map will need to be repeatedly redrawn if we want to analyse experimental publishing's material-discursive practices. At the same time, we are aware of the performative character of our analyses (i.e., how any classification we suggest will provide further authority and weight to that classification), which will inherently be a factor in the stabilising, fixing, and freezing of these practices and knowledge relations, including as part of the mapping or typology that we provide here. One way in which this is very much apparent, is in how 
the first two versions of this report-based on desk research-are written in English and predominantly include English-language examples of experimental books, as well as books published by presses from the Global North. $\underline{1}$ Our aim for subsequent versions of this report is to continue to reach out to publishing networks and communities in the Global South to ensure more diverse examples from different regions and from languages other than English are included and made visible.

We want to publish this report openly in different versions (what you are reading now is the second version of this section of the report, see here for version 1.0), which will enable us to continue updating it and incorporate new examples and classifications. We hope this can become a resource (or an ExPub Compendium, see section 3 of this report for more on this) that is eventually taken up and maintained by the experimental publishing community, or which becomes a reference or starting point for new mappings and analyses of this field (just as the classifications presented in the literature we have consulted and referenced for this report inform the current typology). By keeping this mapping open, both for updates and further uptake by the community, we hope we can prevent a too stringently fixing-down of the speculative character of these experiments, where instead we want to emphasise that its political nature lies in the book continuing "to be able to serve "new ends" as a medium through which politics itself can be rethought' (Adema \& Hall, 2013; Drucker, 2004). 2 Indeed, experimental publishing can be seen as an attempt at keeping 'open the politics of knowledge and communication in a context in which these are being closed down'. (Kember, 2014).

We are aware that by not making the argument for a stable or conclusive taxonomy we are going against the grain of those who argue that (further) solidification and standardisation of forms is necessary to enable experimental and speculative publications to be incorporated into our established measurement, metric, and evaluation systems (ㅁpence,2018,_p. 12). Walkowski,_2019). However, this is not a oneway direction and we would rather emphasise the opposite: measurement and evaluation systems will need to adapt and be rethought to accommodate new forms of publication in a continuous manner. One of the underlying aims of experimental publishing has always been to rethink, reimagine, and critique the forms, structures, and systems that underlie our system of scholarly communication and to work towards forms and relations that might better suit our diverse forms of research and support the conversations around it. As Tara McPherson argues, evolving 'more "standardized" structures and interfaces that will allow us to delineate more stable genres and to scale multimodal scholarship,' should not stand in the way of exploring new modes of 
scholarship and publishing, where McPherson emphasises the ongoing need for forms of bold experimentation (McPherson, 2010). In this sense we believe space needs to be provided to these forms to actually experiment and intervene (for opacity and disorientation) beyond institutionalising measures that fix these experiments down again.

\section{Situating Experimental Books}

Following this line of thinking, instead of defining what makes an experimental book or what constitutes experimental publishing, we would like to position it here in relation to certain practices and contexts instead. For example, what becomes clear when trying to situate experimental book publishing within academia, is that it finds itself (historically) positioned across 3 different, yet interconnected discourses: around the codex format, around digital publishing, and around openness.

The codex format or the printed book continues to play an important role in future imaginaries of the scholarly book. For example, many experiments (as well as classifications of experiments) tend to start off from a binary position, either as a response to, departure from, or enhancement of the printed book. In other words, in debates on the future of the scholarly book, often comparisons are made with the printed book, which scholars continue to perceive as an essential form for long-form scholarship in the humanities (C.Collins \& Milloy,_2016). Experimental works are often valued according to their 'equivalence' to the codex book-whether this is to its form, e.g., print and linear, or to the scholarly practices established around the codex, e.g., single authorship, originality, blind peer review. The codex form then becomes the standard or the benchmark we measure our experiments or enhancements against (instead of valuing them on their own merits). This report does not want to downplay the value of the codex form or what has become the 'standard' fixed and bound book format, which indeed continues to play a crucial role in humanities research and its publishing ecology; nor does this report want to de-emphasise the experimental and political potential of print (Adema \& Hall,2013; Trettien,_2021;(Pold \& Anderson,_ 2014; Adema, 2021). What we want to argue for here however is the 'irreducible plurality of academic publishing' (Kivistö \& Pihlström, 2015,_p.4). and a thinking that moves beyond the discourses and relationalities of print and the codex and tries to explore different forms and ways of relating, which is exactly what experimental publishing as we perceive it sets out to do.

It merits highlighting here again that experimental publishing can incorporate any format or medium, and print has proofed to be a very versatile, experimental, and 
speculative medium throughout its history. However, in the present context, experimental scholarly publishing finds itself situated predominantly in relation to the digital medium and the possibilities this offers for the production, dissemination, and consumption of scholarly research. Some even see digital experimental publishing as the outcome of a linear process, i.e., as a development from the printed to the enhanced monograph and from there to interactive digital-only publishing (Elliott, 2015), or as a in transition 'from' analogue 'to' digital formats-which, as Kember has highlighted, is a false dichotomy (Kember, 2014). Yet when it comes to the monograph, Maxwell et al. (Maxwell, Bordini, and Shamash,2017). and others talk about an 'innovation crisis' (as part of a series of monograph crises), in which the monograph is still stuck in a print paradigm focused on print products-where the journal has been much better in adapting to a digital environment, for example. In addition to that, we need to be wary of the techno-futurist rhetoric that surrounds ideas of 'digital innovation' (ㅁpence, 2018,_p. 12), where narratives of digital innovation tend to focus mainly on strengthening the knowledge economy and often underlie more neoliberal forms of openness. $\underline{3}$ Here the hype of digital innovation and disruption (currently centred mainly around virtual reality, AI, apps, and linked data) can stand in the way of any thorough experimentation with the forms and relationalities of publishing. Especially when a lot of digital publishing, however 'innovative,' still remains a mirroring or remediation of print organisation and processes, and of the codex format. Mrva-Montoya talks about tradigital books in this respect-or what in other contexts has been positioned as postdigital publishing.(Pold \& Anderson,2014; Cramer,2012; Ludovico, 2012).-where most of the backend production processes are digital, yet the outcome is still a print or codex-based product. As Mrva-Montoya states: 'the majority of scholarly book publishers remain focused on monographs and edited collections, released in multiple formats (print, ePub, and so on), but with linear content refined using traditional editing practices and the design driven by the paradigm of the printed page. We are still effectively dealing with "print" books hosted in an online environment' (Mrva-Montoya,_2015,_p. 337). In this respect the digital on its own is not necessarily experimental, especially when in most cases it simply emulates print in appearance and through restricted closed forms of licensing (e.g., DRM). As Maxwell et al. make clear, they 'do not consider the e-book as a significant innovation in monograph publishing' where it is 'effectively an electronic proxy for the printed book' (Maxwell, Bordini, and Shamash,2017). Notwithstanding these mirroring tendencies, there is a felt need among publishers and authors to further explore the potential of the digital medium and of digital publishing tools to experiment with new formats and alternative workflows for publishing, as well as potentially increased possibilities for 
interaction with and collaboration around research and publications, for example with new forms of review and annotation tools (Bertino \& Staines, 2019).

A third context to which we argue experimental publishing should be related is that of open access (OA) publishing and open source software. In many ways OA publishing can be seen as a prerequisite for doing contemporary forms of experimental publishing, which do not bide well by a strict copyright and ownership regime. Bertino and Staines argue for the importance of breaking through proprietary channels to enable human and machine-readable annotations, for example, where openness allows for improved interaction around content (Bertino \& Staines, 2019,_p. 2), and similar arguments can be made about other forms of reuse and remix, and forms of community authoring and reviewing. But, as with the digital medium, the open availability of a work doesn't make it experimental or open for further experimentation and reuse (e.g., due to copyright licenses, platform-enclosures, and other technological, social, and cultural barriers). In this respect, as Mrva-Montoya has argued, innovation in OA publishing has mostly happened on the level of business models and distribution:

'while the open access publishing model is certainly transformational, it is driven by experimenting with the new business, distribution, and permission models rather than with a new format of scholarly communication practice' (MrvaMontoya , 2015,_p. 337).

We can see this most clearly in the adoption of OA by commercial and legacy publishers, often using their own proprietary platforms and open licenses (placing restrictions on certain forms of (data) sharing, mining, and reuse). To promote experimental publishing, it is therefore important that the software, platforms, and infrastructures that support publishing are also open (source), not-for-profit, and community-led, as the COPIM project is arguing for.

In this context several open source publishing tools, software infrastructures, and platforms are being developed at the moment to support experimental publishing. Worthington even describes his work with the Hybrid Publishing Coalition-focused on building public open source software infrastructures for publishing to support the freeflow of knowledge-as a form of 'book liberation' (Worthington, 2015). He argues that book liberation is as much a political issue (around the fear of corporate infrastructure enclosure of both content and infrastructure) as a technical one. But beyond openness and open licenses, upkeep and (financial) support is needed to maintain these public infrastructures and promote diversity in the publishing ecosystem. This involves 
supporting smaller publishers, publishing institutions, projects, local knowledge communities and organisations, by replacing proprietary software with interoperable open source digital workflows-with which, as Worthington states: 'publishers could afford to experiment and innovate' (Worthington, 2015). The same thinking lies behind experimental publishing platforms such as $\underline{\text { Vega }}$, which are focused on accommodating experimental publishing workflows that accommodate webtexts. As Ball and Eyman explain, this platform will be 'open source and modular so that editors and publishers can modify their own installations of this free software based on their own editorial needs and desires'. (Ball \& Eyman, 2015)..$\underline{4}$

These forms of open access, community-supported, not-for-profit, and open source publishing are all the more important for experimental publications, as these often lack a clear market-appeal. Furthermore, as Ortega argues with respect to the publishing of print-digital hybrids, many experiments are also one-offs and are nonscalable. These kinds of experiments 'persist at the margins of large scale commercial publishing' and fit better in the small, independent not-for-profit landscape, she argues, where beyond market failure (and often reader-resistance), technological developments often outpace upkeep, which highlights the importance of community-

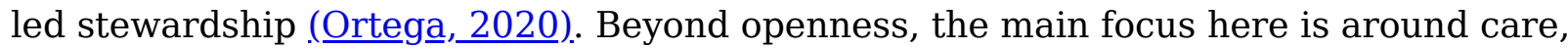
coordination, interoperability, and ecosystem integration, and about stewardship and custodianship (Mars \& Medak, 2019). As Maxwell et al. state, 'who will care about these projects?', and how do they develop from projects to infrastructures, to 'a comprehensive, networked environment' (Maxwell et al.,2019). Similar to Worthington, Maxwell et al. stress that beyond openness and open source software being free, robust alternatives to support (experimental) publishing would 'depend greatly on community practices and the integration of various tools into a broader interoperable context' (Maxwell et al.,2019). And, we would add, to support inclusivity and equitability, these forms of care will have to extend to, as Angela Okune states, 'rethinking how scholarly infrastructures can be decolonised and decentralised for

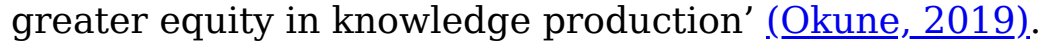

\section{Experimental Scholarship and Experimental Books}

As outlined above, experimental forms and practices of publishing open up and explore questions around modalities, linearity, workflow, and the relationalities of publishing; they examine established practices that we have often been taking for granted or have been repeating uncritically within conventional forms of publishing-where they have become solidified in standard print- and codex-based publishing forms and practices. 
This especially also concerns discussions about what constitutes a publication, or at what point scholarship is formally 'published' (the current consensus is that a book is published once it is peer reviewed and published by a reputable press). Given the diversity of forms and formats (e.g., from screen-based works to visualisations and interactive archives and databases) in experimental publishing, and the fact that digital and experimental scholarship is often a communal endeavour that undergoes community review, is often developed openly online, and is not always formally published by a press, it can be hard to distinguish between scholarship and publication. Conventions around this, which again are often actively questioned in form and practice, are less well established within digital and experimental forms of publishing. This leads to comparisons being made with practices established around the printed codex form (e.g., blind peer review, (copy-)editing, print availability), which are then often perceived as the standard to emulate. $\underline{5}$ Instead, what might be more interesting, is to track how guidelines around evaluating digital and multimodal scholarship and publications are being established within different fields and amongst different scholarly communities. Guidelines focused on evaluating works on their own merits, in the media they are produced, in an ongoing manner, and including technical, design, computational, and interface elements in their evaluation-including reviews of digital humanities projects, archives, tools, and resources (Anderson \& McPherson,_2011; Risam, 2014; Guiliano \& Risam, 2019; Nyhan, 2020).

This report does however focus on experimental publications (or to be more precise, on experimental books). The importance of a 'publishing function' (without wanting to indicate who should or can fulfil this function) here is that it helps us distinguish between scholarship and publication, and can help decide or indicate when something is published-and publishing of course doesn't have to be a one-off occasion, as publications can also be versioned or processual. Having discussions on when we make publishing decisions, and for what reason (e.g., to communicate, ask for feedback, for promotion and career reasons, to claim, to market, to sell) and who makes these decisions (e.g., a publisher or formal publishing entity, an author or group of authors, a scholarly community or field), is something that needs to happen within our fields and scholarly communities. The above sketched uncertainty on how to answer these questions for experimental forms of publishing does not absolve us from making these kinds of decisions, even though much experimental scholarship is focused on breaking down barriers between process and product, formal and informal publications, for example. As Elliott states in this respect: 
'One of our challenges in discussing the future of publication in the humanities has been in distinguishing between digital publication and digital scholarship' (Elliott, 2015).

However, again, where Elliott and others formulate-or argue for the formulation ofclear definitions to distinguish both, we don't want to do so here, for the simple reason that this depends on the research itself, and on field-specific contexts and discourses. Fixed definitions don't always make it easier to make these kinds of decisions (e.g., when is something reviewed? By whom and in what way, and to what end?), and might close down these conversations that different scholarly communities will have to have to determine their own (what we hope are contingent and continuously reviewed) understandings around what constitutes a book or a publication.

\section{Naming Conventions}

In this report we talk about experimental publishing and experimental books, which is one way of coining a mode of publishing that in other contexts might be called multimodal, screen-based, or interactive publishing. Our preference for using experimental publishing is that is it both a wider and more inclusive term that includes multi-modal, interactive, and screen-based works, while not restricting which media forms or practices are included in experimental forms of publishing. Experimental publishing as a term and practice also broadens out discussion from what these forms of publishing are to what they do, e.g. experiment, speculate, reimagine, question, critique (established publishing forms and practices). Although we feel experimental publishing functions well as an overarching term, $\underline{6}$ it again becomes more complicated once we name different types of experimental publications. Experimental publishing happens within a wide-range of fields (digital humanities, digital rhetorics, media studies, e-literature, conceptual poetry, creative writing, and artists' books publishing, etc. have been at the vanguard), often with different established naming-conventions

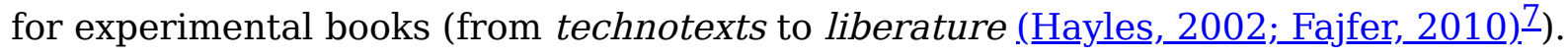
Naming-conventions are also often again coined in relation or with reference to the printed book or codex format (for example, as an add-on: e-books or digital monographs, or enhanced books), where, as with the categorisations mentioned before, there is a tendency to make these terms more uniform and less ambiguous, or to work towards more stabilised or generally accepted names for specific forms of experimental publishing (Spence, 2018,_p. 12). This research instead argues for a plurality of terms and instead of fixing a corpus of terms to identify different experimental publishing forms, will mention or reference these variously used terms 
throughout this report and the accompanying typology. We want to highlight a couple of these terms here, because similar to 'experimental publishing' they are more overarching terms, and because they define experimental publishing not in relation to the printed book, but in relation to the web.

One quite widely used term is networked books; albeit perhaps slightly dated now, as a concept this was used within the context of the ground-breaking research of the Institute for the Future of the Book (If:book). If:book saw Wikipedia as a networked book par excellence and described a networked book as open, disaggregated, social, and processed (Vershbow,_2006; White,2006; Esposito,_2003). Mrva-Montoya defines it as a book that is 'written, edited, and read in a networked environment that emphasizes author-reader interaction' (Mrva-Montoya,_2015,_p. 337). The term 'networked book' was used to describe Wark's versioned or processual book Gamer Theory and Fitzpatrick's openly reviewed Planned Obsolesence, for example.

Another popular term is webtexts, which is predominantly used within the field of digital rhetorics, $\underline{8}$ referring mainly to interactive publications and multi-linear works. Ball and Eyman explain that 'webtexts are multimedia-rich, digital, screen-based texts designed to enact an author's scholarly argument' (Ball \& Eyman, 2015). For Ball and Eyman, as we will discuss in the next section, webtexts require a different relation of editors and publishers to a publication, calling for their own workflow to support multimedia designs.

A final term we would like to highlight here is emergent genres, used by Tara McPherson to describe the work she has done with the experimental journal Vectors, as both 'formally challenging and [work] that explores the boundaries of what might count as scholarly argument' (McPherson, 2010). This echoes the work of media theorist Katherine Hayles, who has argued that materiality is an emergent property, something that cannot be specified in advance and that, as such, is not a pre-given entity (ㅂyles, 2004,_p. 72). For McPherson-examining the boundaries between creative expression and scholarship-emergent genres 'better take advantage of the affordances of computation,' which includes investigating 'bold new forms of experimentation and bookishness' to push scholarly publishing in the humanities further (McPherson, 2010). The open-ended terminology used by McPherson here is one we feel fits well with experimental publishing practices. 


\section{Material Agency}

If experimental forms of publishing make one thing clear, it is that content and form are entangled (i.e., media forms, workflows, and infrastructures are never 'neutral'). The agency and performativity of our technologies and media formats needs to be taken into consideration when we experiment with new forms of publishing (as they should in a print environment, where they are nonetheless often perceived as 'natural'). As Helms argues with respect to digital scholarly monographs or experimental formats, authors need to pay 'special attention to the eventual form of their work at every stage, from writing a proposal to eventual publication' (Helms, 2018). Nevertheless, there are still those who think that setting up a dichotomy between the monograph as form and content is 'an advantageous strategy when considering the academic book of the future' (O'Sullivan, 2018,_p. 494). As Ball and Eyman make clear though, building on their more than 15 years of experience editing scholarly multimedia: 'you cannot separate form and content-or the written content from its design.' (...) 'This process of removing content runs counter to the purpose of scholarly multimedia in which form and content are inseparable' (Ball \& Eyman, 2015). They and others indicate in this respect that separating form from content 'result[s] in a loss of meaning' (․ Helms, 2018), especially in copy-editing processes. It is important to also highlight media and machinic agency in these processes, where Maxwell et al. outline that platforms such as Omeka, Scalar, and Mukurtu 'are part of the discourse around the nature of the book in an online context' (Maxwell et al.,2019). and Worthington talks about the importance of machinic agency in the publishing workflow:

'the reader as receiver or consumer is only one role to consider. (...) real-time collaborative text editors - GDocs, Fidus Writer, Etherpad, Ethertoff - change the skill set of the user, change the interface of the publication from read only to read/write, and so intervene in the intimacy of the act of authoring' (Worthington, $\underline{2015})$.

In this sense the book has never 'merely' been a symbolic form and print never 'only' a carrier of information. Similarly, our critical scholarly practices, developed over the centuries, have inherently been shaped by the media we use to communicate our research, hence they are also not something we can easily 'extract' from our print media to then apply to a digital context, as the digital again changes what these critical practices are or could potentially be. 


\section{Reimagining Roles and Relationalities}

Related to this, many experimental publications involve a rethinking of how we organise scholarship, its roles, and relationships (e.g., authorship, ownership, the publishing function), highlighting that these processes, workflows, and relationalities are not neutral but have been historically formed and developed as part of the development of the codex format. However, new relationalities do not always have to result in experimental forms or in experimental outputs. Similarly, the production of the printed book has always involved collaborations between various parties and stakeholders and different human and machinic agencies. Yet these processes still mainly revolve around the printed book object, closed and copyrighted with linear content written by a single author. New roles in a digital workflow don't necessarily change this if the outcome is still based on the printed book format. As Mrva-Montoya argues,

'while researchers are working with new tools and technologies, in increasingly collaborative environments, the research outputs still need to be published in a format that complies with the various academic evaluation processes around the world, which typically means a book, a book chapter, a journal article, or a conference paper in a printed or digital format' (Mrva-Montoya, 2015,_p. 337).

This process is set up in a fairly linear way where the development of experimental digital works 'involve far more complex, non-linear, and iterative processes and require a close collaboration from an early stage of conceptual work' (Mrva-Montoya, 2015,_p. 337).

Presses tend to play a different and often much more involved role in developing digital projects than they do in print ones, as do other agencies within our academic institutions (e.g., librarians, technologists, designers). Kral and Worthington in this respect talk about experimental publishing within the post-digital condition 'blurring the distinction between the publishers workflow and the scholars textual creation', which for them also means 'an expansion of the very definition what constitutes a publication' (Kral \& Worthington, 2014). This reimagined relationship between authors and publishers was one of the main findings of the ground-breaking Gutenberg-e program, one of the first projects (starting in 1999) exploring how to enable 'enhanced forms of historical scholarship and writing through the use of digital technologies' (Wittenberg, 2009,_p. 39). They quickly found that authors needed more help with envisioning what a digital, enhanced monograph could look like, while presses needed to get a better grip on the complexity of the specific editorial and technical aspects 
that these forms of publishing need. This 'required a kind of collaboration among authors, editors, and technical staff that is quite different from the traditional publishing process' (Wittenberg,_2009,_p. 39). As Wittenberg argues, the collaboration that was subsequently established, was one of the most interesting and valuable outcomes of the project, resulting in the publication of highly original innovative works, where 'authors and their publishers became active partners in the creation of new models of scholarly communication' (Wittenberg,_2009,_p. 39).

Ball and Eyman have outlined in depth how experimental publishing involves a reconfiguring of the editorial workflow. As they state:

'This problem - how multimedia-based scholarship is edited and by whom - has been a perpetual refrain in conversations we have had with journal and press editors moving into multimedia publishing realms' (Ball \& Eyman, 2015).

What will increasingly be needed, they explain, are forms of design editing, which 'accommodate[s] evaluation of the rhetorical considerations of a design as a whole while also ensuring a design's accessibility, sustainability, and usability through attention to the underlying technical specifications.' As they state, the kinds of workflows necessary for experimental scholarly publishing generally include both development and production, which involve models of presses and editors working collaboratively with authors prior to official submission. They explain that

'this makes for a much more recursive composing process for the text, where authors and editors tend to work more closely together to get a webtext ready for submission or publication'.(Ball \& Eyman, 2015).

Next to changing relationalities between presses and authors, experimental forms of publishing also often involve changing relations with other scholars and scholarly communities. New forms of collaboration around texts, such as commenting, annotating, and open and collaborative reviewing, are some of the more well-known enhancements currently being experimented with in this respect. Open and community review can even be seen as a necessity with experimental publishing, where many projects develop online first and authors are often easily identifiable or even embedded within publications (i.e., via voice overs and videos). Community review has the potential to counter bias in this respect, where Ball and Eyman conclude that: 'doubleblind or anonymous review of scholarly multimedia is impractical. Peer reviewers will know who the author is'. (Ball \& Eyman, 2015). 
These collaborations around and even on texts in the case of openly editable or community authored works, are increasingly acknowledged as forms of distributed authorship, disrupting the myth of single individual authorship upheld within codex book publishing, and expanding ideas of what counts as authorship on texts. As Hall argues with respect to openly editable wiki-books, for example:

'wiki-communication can enable us to produce a multiplicitous academic and publishing network, one with a far more complex, fluid, antagonistic, distributed, and decentred structure, with a variety of singular and plural, human and nonhuman actants and agents' (빈,2009: 43).

This also again emphasises the different roles and relationalities that come with multimodal and experimental publishing, where scholars instead of standing at the centre of a work or its development, often work together with 'designers, developers, editors, and librarians to start new projects, not merely to finish them' (Maxwell, Bordini, and Shamash,2017). Maxwell et al. describe Nicholas Bauch's interactive digital monograph Enchanting the Desert in this context, which emerged from a collaboration between Stanford University's Centre for Spatial and Textual Analysis and Stanford University Press and credits a team of nearly thirty contributors. Maxwell et al. point out that the role of the press here was a different one, more focused on reviewing, credentialing, and branding and less on traditional production and design elements, which were planned within the university (Maxwell, Bordini, and Shamash, 2017). Riva similarly talks about the key authorial role of designers in multimodal works, where solutions on design issues 'necessarily come from a collaborative effort in which the technologists working on the design and production of the digital monograph have a key "authorial" role' (Riva, 2017), and Elliott emphasises that digital scholarship centres within universities (and we could add libraries here too) play important roles in enabling experimental publishing to thrive (Elliott, 2015).

What is interesting is that Maxwell et al., as well as others, emphasise that, although its role is fluctuating in experimental publishing, the university press's position remains bedrock,

'its centrality seems unquestioned. No matter how scholarly publishing changes whether because of digital scholarship, open access, front-end funding, iterative publications, mass collaboration, or mass consolidation - there is an expectation that the university press will be there' (Maxwell, Bordini, and Shamash, 2017). 
Riva agrees that university presses will continue to play a crucial role, but if they want to continue to do so 'they have to take this partnership with scholars and libraries and these experiments in innovation seriously and not retreat into a "business as usual" kind of short-term thinking' (․iva, 2017). In this respect the reimagined monograph, as Humphreys et al. argue 'will not be built in a single step or by a single organization' (Humphreys et al.,2018). Collaboration between libraries, publishers, scholars, scholarly societies, developers, and technology providers will be important to support experimental publishing. But what remains clear from these changing relationalities, is that what is central here is-again-care, or, as Maxwell et al. state 'communities of people who care-either as developers, supporters, or as users' (Maxwell et al.,2019). Extending and distributing care to multiple groups and institution might be one way to keep experimental projects alive, developing projects into networked environments cared for by communities. As Maxwell et al. make clear, the difference here between for-profit market driven models and community-led models, is that the former look for control of workflows and products, where for not-for-profits stewardship is the central value (Maxwell et al.,2019). One of the benefits of open source development is that many of the software communities, platforms, and digital tool developers involved in supporting experimentation around books, also see themselves as inherently open to collaboration and to forming networks. As Worthington argues with respect to the Hybrid Publishing Group, for example:

'It is important to emphasize is that the HPC is not a fixed and finalised group and we are only at the beginning of forming the network. We want to invite more people to join. The plan is for long term collaboration with a network of stakeholders to support Open Source infrastructures for transmedia, multi-format, scholarly publishing' (Worthington, 2015).

In this sense for experimental publishing to be taken up more widely, this is not only an issue of tools and technologies, or about editorial innovation, but, as one of the Gutenberg-e authors wrote, a wider 'socio-professional' issue, where these new forms of collaboration are 'not only a historical innovation but also an important statement of academic values and ethos' (Wittenberg,_2009,_p. 39).

\section{Works Cited}

Adema, J. (2021). Living Books: Experiments in the Posthumanities. MIT Press. Adema, J. (2015). Knowledge Production Beyond The Book? Performing the Scholarly Monograph in Contemporary Digital Culture [Coventry University]. 
http://curve.coventry.ac.uk/open/items/8222ccb2-f6b0-4e5f-90de-f4c62c77ac86/1/

Adema, J., \& Hall, G. (2013). The Political Nature of the Book: On Artists' Books and Radical Open Access. New Formations, 78(1), 138-156.

https://doi.org/10.3898/NewF.78.07.2013

Adema, J., \& Stone, G. (2017). Changing publishing ecologies: A landscape study of new university presses and academic-led publishing. Jisc.

https://doi.org/10.5281/zenodo.4420993

Anderson, S., \& McPherson, T. (2011). Engaging Digital Scholarship: Thoughts on Evaluating Multimedia Scholarship. Profession, 2011(1), 136-151.

https://doi.org/10.1632/prof.2011.2011.1.136

Ball, C. E., \& Eyman, D. (2015). Editorial Workflows for Multimedia-Rich Scholarship. Journal of Electronic Publishing, 18(4). https://doi.org/10.3998/3336451.0018.406

Bertino, A. C., \& Staines, H. (2019). Enabling A Conversation Across Scholarly Monographs through Open Annotation. Publications, 7(2), 41. https://doi.org/10.3390/publications7020041

Biagioli, M. (2002). From Book Censorship to Academic Peer Review. Emergences: Journal for the Study of Media \& Composite Cultures, 12(1), 11-45. https://doi.org/10.1080/1045722022000003435

Collins, E., \& Milloy, C. (2016). OAPEN-UK Final Report: A five-year study into open access monograph publishing in the humanities and social sciences. Jisc. https://oapen.fra1.digitaloceanspaces.com/7a65d73f1087444d80807833a320fa36.pdf Cramer, F. (2012). Post-Digital Writing. Electronic Book Review. https://web.archive.org/web/20180415171734/http://www.electronicbookreview.com/thr ead/electropoetics/postal

Drucker, J. (2004). The Century of Artists' Books (2nd ed.). Granary Books.

Elliott, M. A. (2015). The Future of The Monograph in the Digital Era: A Report to the Andrew W. Mellon Foundation. Journal of Electronic Publishing, 18(4).

https://doi.org/10.3998/3336451.0018.407

Esposito, J. J. (2003, March 3). The processed book (1996 - 2003) [Text]. First Monday, ISSN 1396-0466; Valauskas, Edward J. 
https://journals.uic.edu/ojs/index.php/fm/article/download/1038/959?inline=1

Fajfer, Z. (2010). Liberature or Total Literature. Collected Essays 1999-2009 (K. Bazarnik, Ed.).

Guiliano, J., \& Risam, R. (2019). Introduction. Reviews in Digital Humanities, I(1). https://doi.org/10.21428/3e88f64f.941f9859

Hall, G. (2009). Fluid notes on liquid books. In Putting Knowledge to Work and Letting Information Play: The Center for Digital Discourse and Culture (Timothy W. Luke and Jeremy Hunsinger).

Hayles, N. K. (2002). Writing machines. MIT Press.

Hayles, N. K. (2004). Print Is Flat, Code Is Deep: The Importance of Media-Specific Analysis. Poetics Today, 25(1), 67-90. https://doi.org/10.1215/03335372-25-1-67

Helms, J. (2018). Making Rhizcomics. Kairos. A Journal of Rhetoric, Technology, and Pedagogy, 23(1). http://kairos.technorhetoric.net/23.1/inventio/helms/

Humphreys, A., Spencer, C., Brown, L., Loy, M., \& Snyder, R. (2018). Reimagining the Digital Monograph: Design Thinking to Build New Tools for Researchers. Journal of Electronic Publishing, 21(1). https://doi.org/10.3998/3336451.0021.102

Kember, S. (2014, April 21). Opening Out from Open Access: Writing and Publishing in Response to Neoliberalism. Ada: A Journal of Gender, New Media, and Technology. http://adanewmedia.org/2014/04/issue4-kember/

Kivistö, S., \& Pihlström, S. (2015). The monograph-An old-fashioned publication forum or an ultimate scholarly achievement? (p. 26). University of Helsinki. https://researchportal.helsinki.fi/en/publications/the-monograph-an-old-fashionedpublication-forum-or-an-ultimate-s-2

Kral, C., \& Worthington, S. (2014). A Publication Taxonomy. Hybrid Publishing Consortium. https://research.consortium.io/docs/a_publication taxonomy/a-publicationtaxonomy.html

Ludovico, A. (2012). Post-Digital Print-The Mutation of Publishing Since 1984 (1st ed.). Onomatopee.

Mars, M., \& Medak, T. (2019). Against innovation: Compromised institutional agency and acts of custodianship. Ephemera: Theory \& Politics in Organization, 19(2), 24. 
Maxwell, J. W., Bordini, A., \& Shamash, K. (2017). Reassembling Scholarly Communications: An Evaluation of the Andrew W. Mellon Foundation's Monograph Initiative (Final Report, May 2016). Journal of Electronic Publishing, 20(1). https://doi.org/10.3998/3336451.0020.101

Maxwell, J. W., Hanson, E., Desai, L., Tiampo, C., O’Donnell, K., Ketheeswaran, A., Sun, M., Walter, E., \& Michelle, E. (2019). Mind the Gap: A Landscape Analysis of Open Source Publishing Tools and Platforms. PubPub.

https://doi.org/10.21428/6bc8b38c.2e2f6c3f

McDonald, F., \& Trettien, W. (n.d.). Manifesto. Thresholds. Retrieved 26 June 2020, from http://openthresholds.org/manifesto

McPherson, T. (2010). Scaling Vectors: Thoughts on the Future of Scholarly Communication. Journal of Electronic Publishing, 13(2).

https://doi.org/10.3998/3336451.0013.208

Moxham, N., \& Fyfe, A. (2018). The Royal Society and the Prehistory of Peer Review, 1665-1965. The Historical Journal, 61(4), 863-889.

https://doi.org/10.1017/S0018246X17000334

Mrva-Montoya, A. (2015). Beyond the Monograph: Publishing Research for Multimedia and Multiplatform Delivery. Journal of Scholarly Publishing.

https://doi.org/10.3138/jsp.46.4.02

Nyhan, J. (2020). The Evaluation and Peer Review of Digital Scholarship in the Humanities: Experiences, Discussions, and Histories. In J. Edmond (Ed.), Digital Technology and the Practices of Humanities Research (pp. 163-182). Open Book Publishers. https://doi.org/10.11647/obp.0192.07

Okune, A. (2019, May 29). Decolonizing scholarly data and publishing infrastructures. Africa at LSE. https://blogs.lse.ac.uk/africaatlse/2019/05/29/decolonizing-scholarly_ data-and-publishing-infrastructures/

Okune, A., Hillyer, R., Albornoz, D., Posada, A., \& Chan, L. (2018, June 20). Whose Infrastructure? Towards Inclusive and Collaborative Knowledge Infrastructures in Open Science. ELPUB 2018, Toronto.

https://doi.org/10.4000/proceedings.elpub.2018.31

Ortega, É. (2020). The Many Books of the Future: Print-digital Literatures. Post45, Ecologies of Neoliberal Publishing. http://post45.org/2020/04/the-many-books-of-the- 
future-print-digital-literatures/

O'Sullivan, J. (2018). The equivalence of books: Monographs, prestige, and the rise of edge cases. Convergence, 24(5), 494-503. https://doi.org/10.1177/1354856518780457

Pold, S. B., \& Anderson, C. U. (2014, June 19). Post-digital Books and Disruptive Literary Machines. Hold the Light: the 2014 ELO Conference, Milwaukee, Wisconsin. http://conference.eliterature.org/critical-writing/post-digital-books-and-disruptiveliterary-machines

Risam, R. (2014). Rethinking Peer Review in the Age of Digital Humanities. Ada: A Journal of Gender, New Media, and Technology, 4. https://doi.org/10.7264/n3wq0220

Riva, M. (2017). An Emerging Scholarly Form: The Digital Monograph. DigitCult Scientific Journal on Digital Cultures, 2(3), 63-74.

https://doi.org/10.4399/97888255099087

Spence, P. (2018). The academic book and its digital dilemmas. Convergence, 24(5), 458-476. https://doi.org/10.1177/1354856518772029

Trettien, W. (2021). Cut/Copy/Paste. Fragments of History. University Of Minnesota Press. https://www.upress.umn.edu/book-division/books/cut-copy_paste \& https://manifold.umn.edu/projects/cut-copy_paste

Vershbow, B. (2006, June 19). Defining the networked book: A few thoughts and a list. If:Book. A Project of The Institute for the Future of the Book.

https://web.archive.org/web/20060619045405/http://www.futureofthebook.org/blog/arc hives/2006/05/defining the networked book a.html

Walkowski, N.-O. (2019). Beyond the Flow. meson press. https://doi.org/10.14619/1600

White, K. (2006, October 11). Sorting the Pile: Making Sense of A Networked Archive | Kairosnews. Kairosnews. A Weblog for Discussing Rhetorci, Technology and Pedagogy. https://web.archive.org/web/20061011130155/http://kairosnews.org/node/4328

Wittenberg, K. (2009). The Gutenberg-e project: Opportunities and challenges in publishing born-digital monographs. Learned Publishing, 22(1), 36-41. https://doi.org/10.1087/095315108X378767

Worthington, S. (2015, March 13). Book to the Future [Manifesto]. Hybrid Publishing Consortium. 
https://web.archive.org/web/20150609133850/https://research.consortium.io/docs/book liberation_manifesto/Book_Liberation_Manifesto.html

\section{External resource}

The bibliographies for all parts of this report are openly available on Zotero.

Header image: Screenshot from Méndez Cota, G., Torres, L. E., Toxqui, M. \& Arziniaga, Á. (2016). En Busca del Quelite Perdido. Consejo Nacional para la Cultura y las Artes .

\section{Footnotes}

1. This is partly due to increased investments in recent years by funders in the Global North in multimodal publishing as well as the tools and infrastructures to support this (e.g. by the Mellon Foundation in the US, see Maxwell, Bordini, and Shamash, 2017).

2. As the history of the artist's book shows (and we feel experimental book publications play a similar role in academia), 'it can be used to question, intervene in and disturb existing practices and institutions, and even offer radical, counterinstitutional alternatives' (Adema and Hall, 2013). $\subseteq$

3. As a counterpoint to this various research and publishing efforts that are investigating experimentation as an affirmative speculative practice and critique do so as a means to re-perform our existing scholarly institutions and practices in potentially more ethical and responsible ways (설

4. Several other platforms and infrastructure projects need to be mentioned here, many of which are discussed in Maxwell et al.'s landscape report of open source publishing tools and technologies Mind the Gap. The University of Minnesota Press and CUNY's Manifold platform facilitates processual forms of publishing and captures the ongoing discourse around a book. Older and more well-established

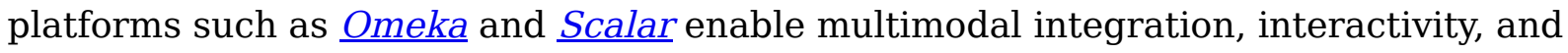
non-linear content organisation. Other systems, less particularly focused on experimental publishing, such as Editoria provide, as Maxwell et al. explain, an editorial and production system for scholarly monographs, where MIT's $\underline{\text { PubPub}}$ 
provides an open source platform to support community publishing (Maxwell et al., 2019).

5. This, however, downplays conversations on the development of evaluation within the print realm as the book in its print form and the practices around it have always been contested too, and there is no 'natural' state or situation to determine when something is published in a print context either, especially within the humanities (e.g. see the tradition of editorial review in humanities book publishing, and the development of peer review) (Moxham and Fyfe, 2018; Biagioli, 2002).

6. Similarly we prefer using the term 'book' in our typology instead of 'work' or text' or 'publication' (although we will also use these terms on occasion) as 'book' as a concept and practice has been able to incorporate a wide variety of forms, hence we think it will be able to incorporate the more experimental forms this report incorporates too. $\subseteq$

7. Walkowksi lists various concepts used in the period after 2007, from liquid publications to unbound books and transmedia publications (Walkowski 2019, p. 53).

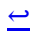

8. See in this context the experimental journal Kairos, the first academic journal to publish multimedia texts. $ヒ$

\section{Citations}

1. Adema, J., \& Stone, G. (2017). Changing publishing ecologies: A landscape study of new university presses and academic-led publishing. http://doi.org/10.5281/zenodo.4420993

2. Okune, A., Hillyer, R., Albornoz, D., Posada, A., \& Chan, L. (2018, June). Whose Infrastructure? Towards Inclusive and Collaborative Knowledge Infrastructures in Open Science. 10.4000/proceedings.elpub.2018.31 3. Adema, J., \& Hall, G. (2013). The Political Nature of the Book: On Artists' Books and Radical Open Access. New Formations, 78(1), 138-156.

https://doi.org/10.3898/NewF.78.07.2013

4. Drucker, J. (2004). The Century of Artists' Books (2nd ed.). Granary Books. 5. Kember, S. (2014). Opening Out from Open Access: Writing and Publishing in Response to Neoliberalism. In Ada: A Journal of Gender, New Media, and 
Technology. http://adanewmedia.org/2014/04/issue4-kember/e

6. Spence, P. (2018). The academic book and its digital dilemmas. Convergence, 24(5), 458-476. https://doi.org/10.1177/1354856518772029

7. Walkowski, N.-O. (2019). Beyond the Flow. meson press. $\unlhd$

8. McPherson, T. (2010). Scaling Vectors: Thoughts on the Future of Scholarly

Communication. Journal of Electronic Publishing, 13(2).

https://doi.org/10.3998/3336451.0013.208

9. Collins, E., \& Milloy, C. (2016). OAPEN-UK Final Report: A five-year study into open access monograph publishing in the humanities and social sciences.

https://oapen.fra1.digitaloceanspaces.com/7a65d73f1087444d80807833a320fa36.pdf

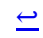

10. Trettien, W. (2021). Cut/Copy/Paste. Fragments of History. University Of Minnesota Press. https://www.upress.umn.edu/book-division/books/cut-copy_paste 11. Pold, S. B., \& Anderson, C. U. (2014, June). Post-digital Books and Disruptive Literary Machines. http://conference.eliterature.org/critical-writing/post-digitalbooks-and-disruptive-literary-machines $\doteq$

12. Adema, J. (2021). Living Books: Experiments in the Posthumanities. MIT Press. 13. Kivistö, S., \& Pihlström, S. (2015). The monograph - an old-fashioned publication forum or an ultimate scholarly achievement?

https://researchportal.helsinki.fi/en/publications/the-monograph-an-old-fashionedpublication-forum-or-an-ultimate-s- $2 \boxminus$

14. Elliott, M. A. (2015). The Future of The Monograph in the Digital Era: A Report to the Andrew W. Mellon Foundation. Journal of Electronic Publishing, 18(4). https://doi.org/10.3998/3336451.0018.407 15. Maxwell, J. W., Bordini, A., \& Shamash, K. (2017). Reassembling Scholarly Communications: An Evaluation of the Andrew W. Mellon Foundation's Monograph Initiative (Final Report, May 2016). Journal of Electronic Publishing, 20(1). https://doi.org/10.3998/3336451.0020.101 16. Cramer, F. (2012). Post-Digital Writing. Electronic Book Review. http://electronicbookreview.com/thread/electropoetics/postal $\triangleq$ 
17. Ludovico, A. (2012). Post-Digital Print - the Mutation of Publishing Since 1984 (1st ed.). Onomatopee. $\_$ 18. Mrva-Montoya, A. (2015). Beyond the Monograph: Publishing Research for Multimedia and Multiplatform Delivery. Journal of Scholarly Publishing. https://doi.org/10.3138/jsp.46.4.02 19. Bertino, A. C., \& Staines, H. (2019). Enabling A Conversation Across Scholarly Monographs through Open Annotation. Publications, 7(2), 41. https://doi.org/10.3390/publications7020041 20. Bertino, A. C., \& Staines, H. (2019). Enabling A Conversation Across Scholarly Monographs through Open Annotation. Publications, 7(2), 41. https://doi.org/10.3390/publications7020041 21. Worthington, S. (2015). Book to the Future. https://research.consortium.io/docs/book_liberation_manifesto/Book_Liberation_Manif esto.html $\triangleq$

22. Ball, C. E., \& Eyman, D. (2015). Editorial Workflows for Multimedia-Rich Scholarship. Journal of Electronic Publishing, 18(4). https://doi.org/10.3998/3336451.0018.406 23. Ortega, É. (2020). The Many Books of the Future: Print-digital Literatures. Post45, Ecologies of Neoliberal Publishing. http://post45.org/2020/04/the-many= books-of-the-future-print-digital-literatures/ $\subseteq$ 24. Mars, M., \& Medak, T. (2019). Against innovation: Compromised institutional agency and acts of custodianship. Ephemera: Theory \&Politics in Organization, 19(2). $\doteq$

25. Maxwell, J. W., Hanson, E., Desai, L., Tiampo, C., O’Donnell, K., Ketheeswaran, A., Sun, M., Walter, E., \& Michelle, E. (2019). Mind the Gap: A Landscape Analysis of Open Source Publishing Tools and Platforms. https://doi.org/10.21428/6bc8b38c.2e2f6c3f $\leftrightharpoons$ 26. Okune, A. (2019). Decolonizing scholarly data and publishing infrastructures. In Africa at LSE. https://blogs.lse.ac.uk/africaatlse/2019/05/29/decolonizing-scholarly= $\underline{\text { data-and-publishing-infrastructures/ }} \triangleq$ 
27. Anderson, S., \& McPherson, T. (2011). Engaging Digital Scholarship: Thoughts on Evaluating Multimedia Scholarship. Profession, 2011(1), 136-151.

https://doi.org/10.1632/prof.2011.2011.1.136

28. Risam, R. (2014). Rethinking Peer Review in the Age of Digital Humanities. Ada:

A Journal of Gender, New Media, and Technology, 4.

https://doi.org/10.7264/n3wq0220

29. Guiliano, J., \& Risam, R. (2019). Introduction. Reviews in Digital Humanities, I(1). https://doi.org/10.21428/3e88f64f.941f9859

30. Nyhan, J. (2020). The Evaluation and Peer Review of Digital Scholarship in the Humanities: Experiences, Discussions, and Histories. In J. Edmond (Ed.), Digital Technology and the Practices of Humanities Research (pp. 163-182). Open Book Publishers. https://doi.org/10.11647/obp.0192.07

31. Hayles, N. K. (2002). Writing machines. MIT Press. $\unlhd$ 32. Fajfer, Z. (2010). Liberature or Total Literature. Collected Essays 1999-2009 (K. Bazarnik, Ed.). $\doteq$

33. Vershbow, B. (2006). Defining the networked book: a few thoughts and a list. In if:book. A project of The Institute for the Future of the Book. https://web.archive.org/web/20060619045405/http://www.futureofthebook.org/blog/a rchives/2006/05/defining the networked book a.html $\doteq$

34. White, K. (2006). Sorting the Pile: Making Sense of A Networked Archive Itextbar Kairosnews. In Kairosnews. A Weblog for Discussing Rhetorci, Technology and Pedagogy. https://web.archive.org/web/20061011130155/http://kairosnews.org/node/4328 35. Esposito, J. J. (2003). The processed book. In First Monday, ISSN 1396-0466. https://journals.uic.edu/ojs/index.php/fm/article/download/1038/959 36. Hayles, N. K. (2004). Print Is Flat, Code Is Deep: The Importance of MediaSpecific Analysis. Poetics Today, 25(1), 67-90. https://doi.org/10.1215/03335372-25-1$\underline{67} \leftrightharpoons$

37. Helms, J. (2018). Making Rhizcomics. Kairos. A Journal of Rhetoric, Technology, and Pedagogy, 23(1). http://kairos.technorhetoric.net/23.1/inventio/helms/ 
38. O’Sullivan, J. (2018). The equivalence of books: Monographs, prestige, and the rise of edge cases. Convergence, 24(5), 494-503.

https://doi.org/10.1177/1354856518780457

39. Kral, C., \& Worthington, S. (2014). A Publication Taxonomy. Hybrid Publishing Consortium. https://research.consortium.io/docs/a_publication taxonomy/apublication-taxonomy.html $\underline{.}$

40. Wittenberg, K. (2009). The Gutenberg-e project: opportunities and challenges in publishing born-digital monographs. Learned Publishing, 22(1), 36-41. https://doi.org/10.1087/095315108X378767

41. Hall, G. (2009). Fluid notes on liquid books. In Putting Knowledge to Work and Letting Information Play: The Center for Digital Discourse and Culture (Timothy W. Luke and Jeremy Hunsinger). $\Xi$

42. Riva, M. (2017). An Emerging Scholarly Form: The Digital Monograph. DigitCult - Scientific Journal on Digital Cultures, 2(3), 63-74.

https://doi.org/10.4399/97888255099087

43. Humphreys, A., Spencer, C., Brown, L., Loy, M., \& Snyder, R. (2018). Reimagining the Digital Monograph: Design Thinking to Build New Tools for Researchers. Journal of Electronic Publishing, 21(1). https://doi.org/10.3998/3336451.0021.102

44. Worthington, S. (2015). Book to the Future.

https://web.archive.org/web/20150609133850/https://research.consortium.io/docs/bo ok liberation manifesto/Book_Liberation_Manifesto.html $\triangleq$ 